\section{Pacific Northwest}

National Laboratory

Operated by Battelle for the

U.S. Department of Energy

\title{
GridLAB-D Technical Support Document: Residential End-Use Module Version 1.0
}

ZT Taylor

K Gowri

S Katipamula

July 2008

Prepared for the U.S. Department of Energy

under Contract DE-AC05-76RL01830 


\title{
DISCLAIMER
}

This report was prepared as an account of work sponsored by an agency of the United States Government. Neither the United States Government nor any agency thereof, nor Battelle Memorial Institute, nor any of their employees, makes any warranty, express or implied, or assumes any legal liability or responsibility for the accuracy, completeness, or usefulness of any information, apparatus, product, or process disclosed, or represents that its use would not infringe privately owned rights. Reference herein to any specific commercial product, process, or service by trade name, trademark, manufacturer, or otherwise does not necessarily constitute or imply its endorsement, recommendation, or favoring by the United States Government or any agency thereof, or Battelle Memorial Institute. The views and opinions of authors expressed herein do not necessarily state or reflect those of the United States Government or any agency thereof.

\author{
PACIFIC NORTHWEST NATIONAL LABORATORY \\ operated by \\ BATTELLE \\ for the \\ UNITED STATES DEPARTMENT OF ENERGY \\ under Contract DE-AC05-76RL01830
}

Printed in the United States of America
Available to DOE and DOE contractors from the Office of Scientific and Technical Information,
P.O. Box 62, Oak Ridge, TN 37831-0062;
ph: (865) 576-8401
fax: (865) 576-5728
email: reports@adonis.osti.gov

\begin{abstract}
Available to the public from the National Technical Information Service, U.S. Department of Commerce, 5285 Port Royal Rd., Springfield, VA 22161 ph: (800) 553-6847 fax: (703) 605-6900 email: orders@ntis.fedworld.gov online ordering: http://www.ntis.gov/ordering.htm
\end{abstract}




\title{
GridLAB-D Technical Support Document: Residential End-Use Module Version 1.0
}

\author{
ZT Taylor \\ K Gowri \\ S Katipamula
}

July 2008

Prepared for

the U.S. Department of Energy

under Contract DE-AC05-76RL01830

Pacific Northwest National Laboratory

Richland, Washington 99352 



\section{Acronyms and Abbreviations}

CFL

CLTD

CPU

ETP

HID

HVAC

ODE

p.u.

SSL

tmy

UA compact fluorescent lighting

cooling load temperature difference

central processing unit

equivalent thermal parameter

high-intensity discharge

heating, ventilation, and air conditioning

ordinary differential equation

per-unit (expressing system quantities as fraction of a defined base unit quantity)

solid-state lighting

typical meteorological year

tank thermal conductance 


\section{Contents}

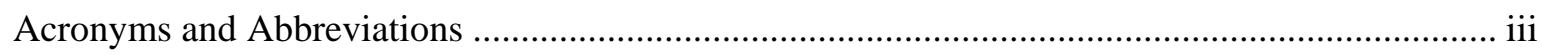

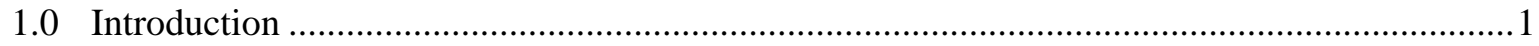

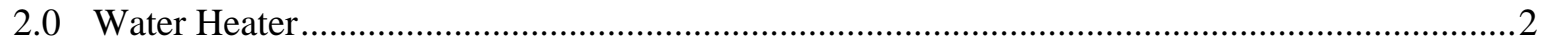

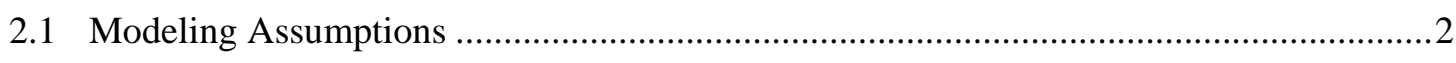

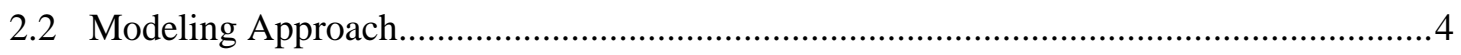

2.2.1 One-Node Temperature Model ……...............................................................6

2.2.2 Two-Node Temperature Model....................................................................

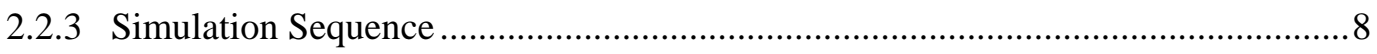

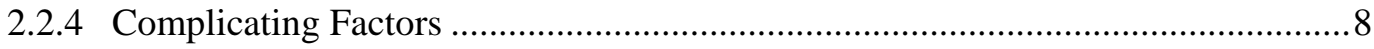

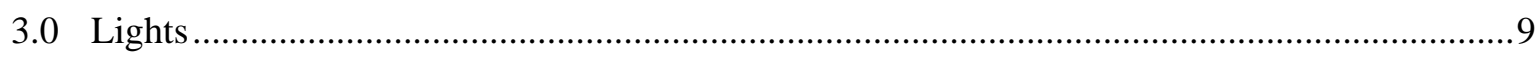

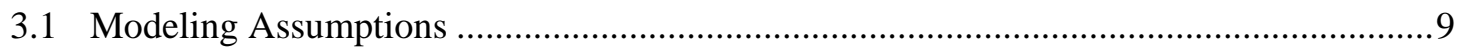

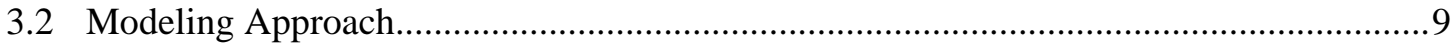

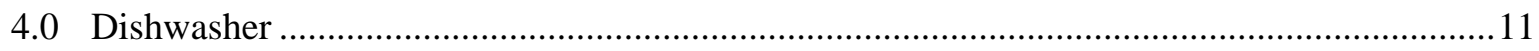

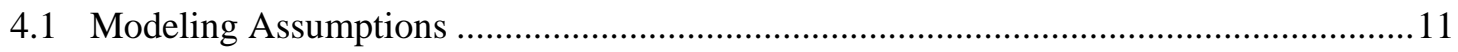

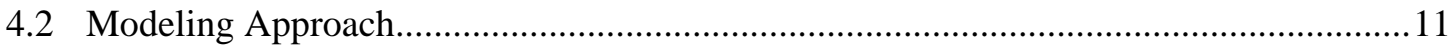

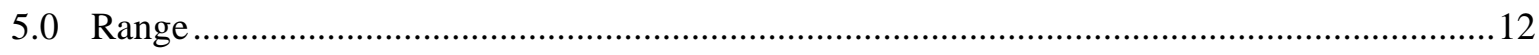

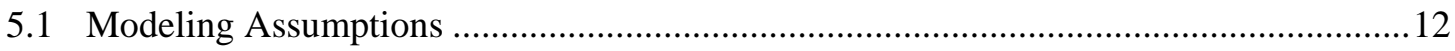

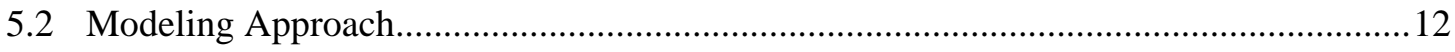

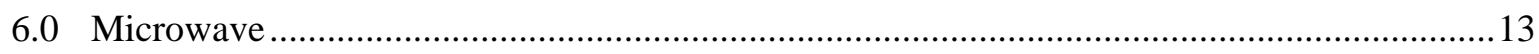

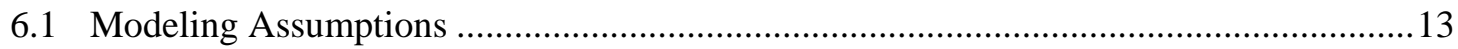

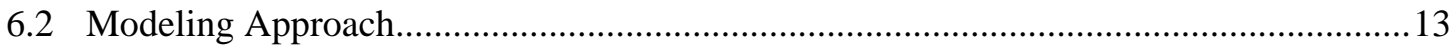

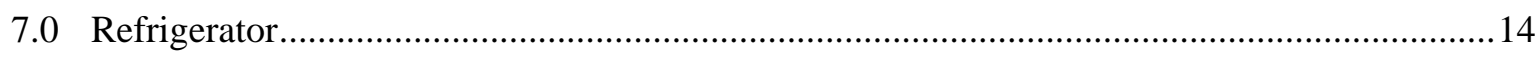

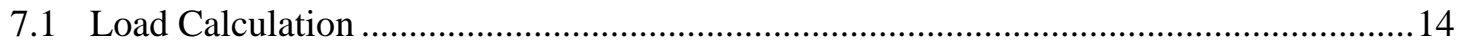

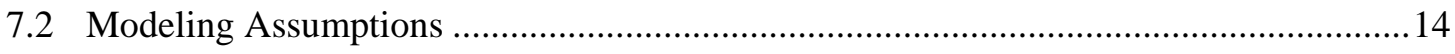

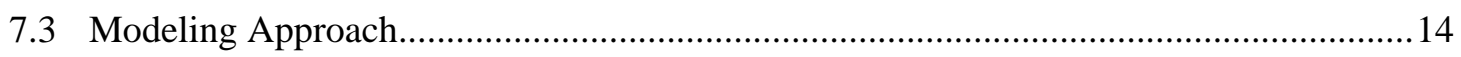

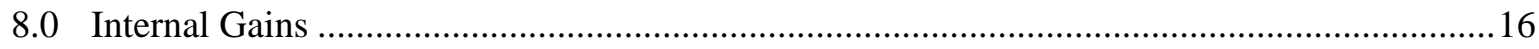

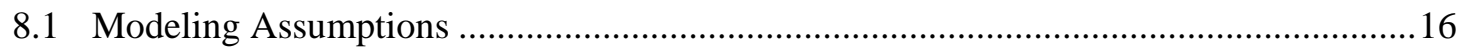

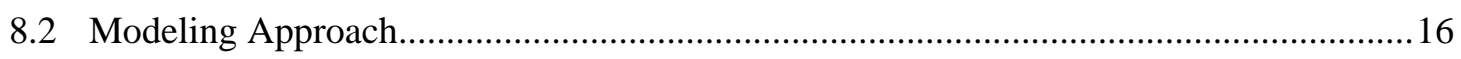

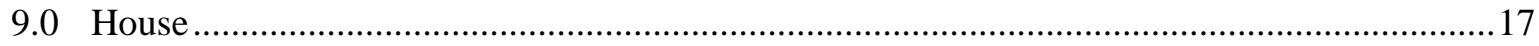

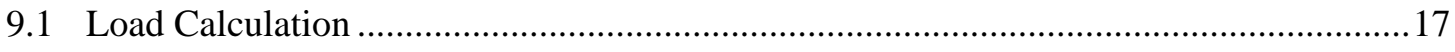

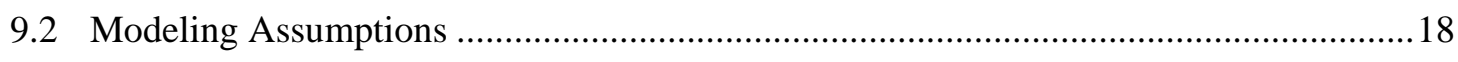

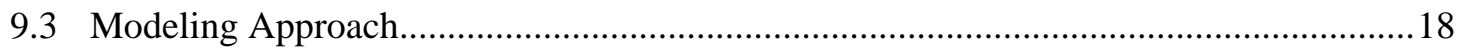

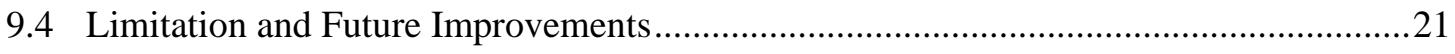

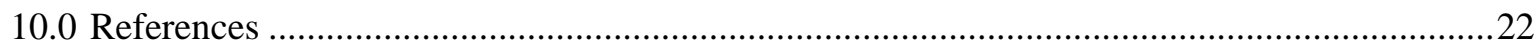




\section{Figures}

Figure 2.1. Illustration of using $\mathrm{dh} / \mathrm{dt}$ to Identify the STABLE State............................................ 5

Figure 2.2. Water Heater Model Schematic Representation.......................................................6

Figure 9.1. ETP Representation of Typical Residences...............................................................19 



\subsection{Introduction}

The residential module implements the following end-uses and characteristics to simulate the power demand in a single family home:

- Water heater

- Lights

- Dishwasher

- Range

- Microwave

- Refrigerator

- Internal gains (plug loads)

- House (heating/cooling loads)

The house model considers the following four major heat gains/losses that contribute to the building heating/cooling load:

1. Conduction through exterior walls, roof and fenestration (based on envelope UA)

2. Air infiltration (based on specified air change rate)

3. Solar radiation (based on CLTD model and using tmy data)

4. Internal gains from lighting, people, equipment and other end-use objects.

The equivalent thermal parameter (ETP) approach is used to model the residential loads and energy consumption. The following sections describe the modeling assumptions for each of the above end-uses and the details of power demand calculations in the residential module. 


\subsection{Water Heater}

Typical residential electric water heaters range in size from about 30 gallons up to 120 gallons, with most tanks falling in the range of about 40 to 80 gallons. Hot water is drawn from the top of the tank to service the home's water loads, with cold make-up water injected near the bottom of the tank. When a hot water draw is in progress, the tank will tend to have a layer of cold water at the bottom.

Water is typically heated by two elements, one located near the bottom of the tank and one located higher in the tank, usually halfway to two-thirds of the way to the top. The lower element shoulders most of the heating load, with the upper element engaging only when the cold water layer has reached it. The two elements are controlled by independent thermostats, but only one is permitted to be on at a time, the upper element having priority. The design is intended to allow rapid (re)heating of the smaller volume of water above the top element so that full-temperature water is available as soon as possible after depletion. Water heater element capacity (wattage) ranges from about $1500 \mathrm{~W}$ to $6000 \mathrm{~W}$, with $4500 \mathrm{~W}$ being common.

Thermostatic controls have a "dead band" associated with the setpoint, which prevents rapid cycling of power to the elements, which would result if the turn-on temperature equaled the turn-off temperature. The dead band is typically a few degrees above and below the nominal setpoint.

Most heaters are shipped with both the upper and lower thermostats set to the same temperature (often $120^{\circ} \mathrm{F}$ ), but they may be modified at installation or a later time. Some manufacturers recommend that if hotter water is desired, only the lower element be set to a higher temperature. This will maintain the entire tank at the higher temperature but allow for rapid recovery of the upper volume to the lower setting following a depletion. The net effect on energy use is negligible if the upper thermostat is set to a lower setting. However, some homeowners wrongly set the upper element to a higher temperature than the lower one, which results in somewhat different behavior. Because of thermal stratification, the upper volume will be maintained at a higher temperature than the lower volume, resulting in somewhat lower standby losses than when the entire tank is heated to the higher setting.

\subsection{Modeling Assumptions}

The GridLAB-D approach to modeling electric water heaters is designed to be computationally fast, yet reasonably accurate. It accommodates the common two-element design and the possibility for inverted thermostat settings, wherein the upper element maintains a higher temperature than the lower element.

To achieve the necessary computational speed, we make the following assumptions:

1. Thermal stratification in the tank is not directly modeled. Depending on the situation, the water will be considered to be either of uniform temperature throughout the tank or "lumped" into two temperature regions (hot and cold layers).

2. The injection of cold inlet water at the bottom of the tank results in either complete mixing with the hot water in the tank or no mixing at all, depending on the volumetric flow rate. 
The water heater simulation uses two very different models depending on the state of the tank at any given moment. The two models are:

1. One-Node Model - This is a simple, lumped-parameter electric analogue model that considers the entire tank to be a single slug of water at a uniform temperature. This model considers the temperature of the water at any given time or the time required for the temperature to move between two specified points.

2. Two-Node Model - This model, which applies when the heater is in a state of partial depletion, considers the heater to consist of two slugs of water, each at a uniform temperature. The upper "hot" node is near the heater's setpoint temperature, while the lower "cold" node is near the inlet water temperature. This model considers the location of the boundary between the hot and cold nodes, calculating the movement of that boundary as hot water is drawn from the tank and/or heat is added to the tank.

The water heater simulation keys on two primary "states" of the water heater:

- Tank State - The tank can be in one of three states:

- FULL - If the water in the tank is at a uniform temperature near the heater's setpoint, the One-Node model applies.

- PARTIAL - If the tank is in a state of partial depletion, where some of the hot water has been (or is being) drawn out, leaving hot and cold layers of water in the tank, the Two-Node model applies.

- EMPTY - If the tank has been completely depleted all the water is at a uniform temperature near the water inlet temperature. Therefore, the One-Node model applies.

- Load State - This refers to the current water load on the heater; that is, whether and how fast hot water is being drawn from the top of the tank. Formally, this load state applies only when the tank state is PARTIAL, but is useful for the FULL and EMPTY tank states because it tells whether the tank will begin to move toward a PARTIAL state or stay in the current state. There are three possible load states:

- DEPLETING - Hot water is being drawn at a rate sufficient to move the boundary between the hot and cold zones upward. That is, hot water is being drawn out faster than the heating element can warm the incoming cold water, so the upper layer of hot water is getting smaller and the lower layer of cold water is getting larger.

- $\quad$ RECOVERING - Hot water is either not being drawn from the tank or is being drawn at a low enough rate that the boundary between the hot and cold layers is moving downward. That is, the hot water is being drawn out at a rate low enough that the heating element can warm the replacement water faster than it is being introduced, causing the upper layer of hot water to get larger and the lower layer of cold water to get smaller.

- STABLE - Simplistically, this state implies that hot water is being drawn at a rate that matches the heating element's ability to warm the incoming cold water. Actually, the hot water draw does not have to exactly match the warming rate for this state to apply. Because there are other heat flows acting on the water (such as jacket losses to surrounding air), in any given situation where the tank state is PARTIAL, there is a range of hot water flow rates for which the tank will never reach either the FULL or the EMPTY state. 
For example, if the tank begins near the FULL state and hot water is drawn from it at a rate slightly higher than the heating element can match, the hot/cold boundary will begin to move upward. However, as the boundary moves upward, the size of the hot layer gets smaller, reducing the area of warm tank that is exposed to the surrounding air. The lowered area means lowered heat losses, which may tip the balance so that the heating element eventually can keep up with the hot water draw. Similarly, starting with an almost empty tank, the heating element's capacity may exceed a small hot water draw and move the hot/cold boundary downward until jacket losses tip the balance. When the load state is STABLE, the calculated time to transition is infinite.

This STABLE state is illustrated in Figure 2.1. For an example water heater, the figure shows the time required to deplete an initially full tank ("time to transition") at various hot water flow rates. Note that flow rates above roughly $0.45 \mathrm{gpm}$ result in positive and finite times to transition. Flow rates below about 0.44 gpm are finite and negative, meaning the tank is not depleting at all but is actually recovering (that is, the heating element can more than keep up with the heat removed by the water draw). Between those two points - between the positive and negative spikes to infinity — the tank is in the STABLE state that will never reach either the FULL or the EMPTY state.

These two critical flow rates depend on many factors, including the tank size and shape, tank thermal conductance (UA), heating element capacity, and the hot and cold layer temperatures. They are identified in the GridLAB-D water heater model by calculating the rate of change of the hot/cold boundary position " $h$ " with respect to time $(d h / d t)$. Note in the lower graphic of Figure 2.1 that the time to transition is positive when $d h / d t$, calculated at the FULL starting point $h 0$, is negative (meaning the tank is depleting). Also note that the time to transition is negative (meaning the tank is really recovering and will remain FULL) when $d h / d t$, calculated at the target EMPTY state, is positive. The area between the two critical flow rates is identified by differing signs between $d h / d t$ calculated at FULL and $d h / d t$ calculated at EMPTY.

\subsection{Modeling Approach}

Figure 2.2 shows a schematic representation of the water heater model in which $T_{\text {avg }}$ is the average water temperature throughout the tank and $T_{a m b}$ is the ambient temperature. The thermal capacitance of the water $C_{w}$ is a function of the tank volume $V$ :

$$
C_{w}=V(g a l) * \frac{1 \mathrm{ft}^{3}}{7.48 \mathrm{gal}} * 62.4 \frac{\mathrm{lb} \mathrm{m}_{\mathrm{m}}}{\mathrm{ft}^{3}} * 1 \frac{\mathrm{Btu}}{\mathrm{lb_{m } \cdot F}}
$$

The thermal conductance of the tank shell (or "jacket") UA is calculated from the known R-values of the sides and top of the tank, divided into their corresponding areas. 

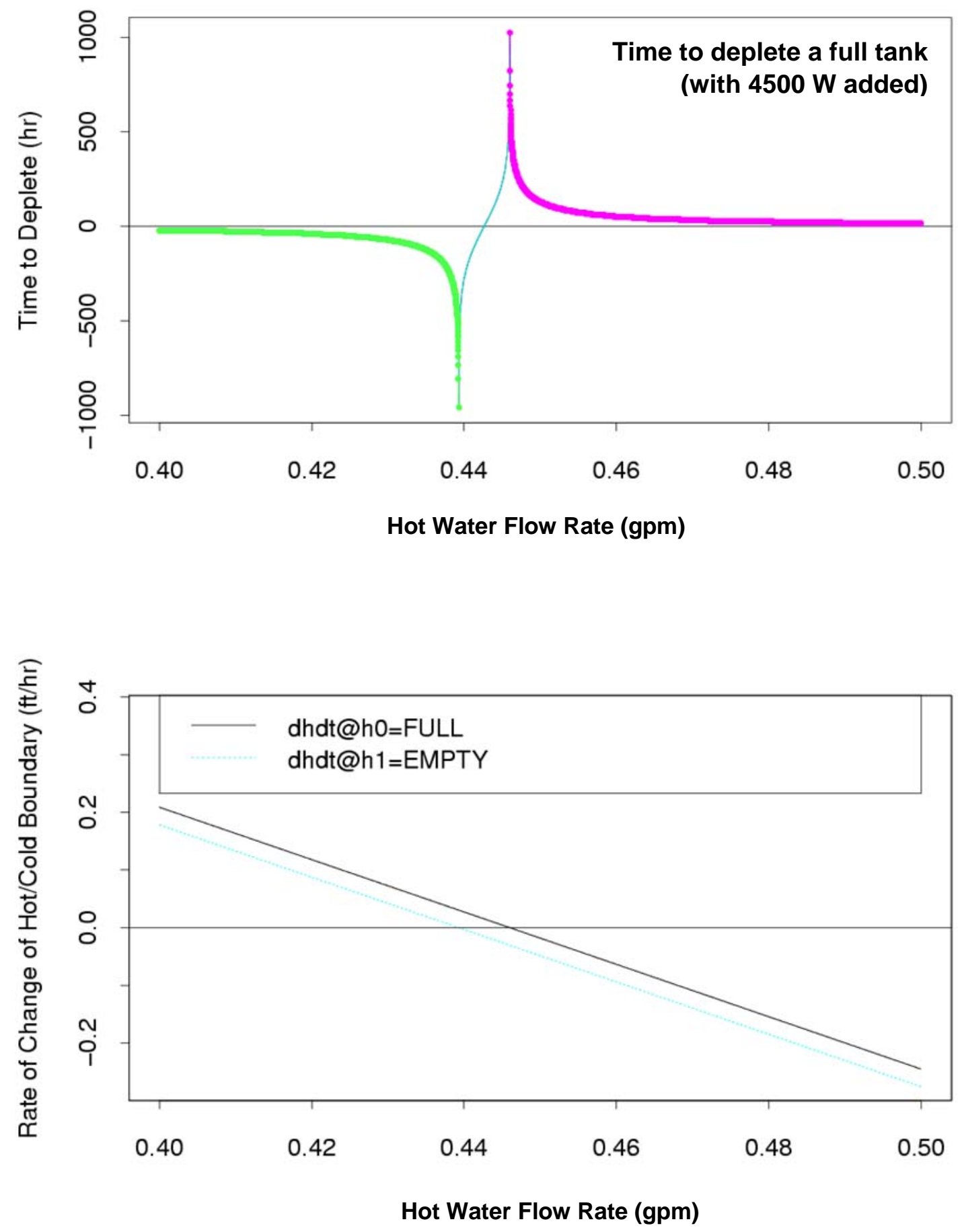

Figure 2.1. Illustration of using $\mathrm{dh} / \mathrm{dt}$ to Identify the STABLE State 


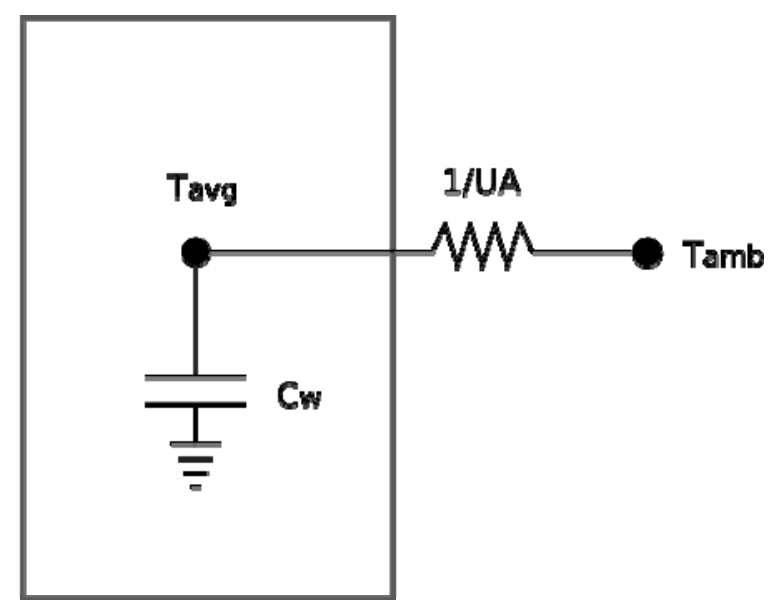

Figure 2.2. Water Heater Model Schematic Representation

\subsubsection{One-Node Temperature Model}

Considering Figure 2.2 and treating the water heater as a single node with thermal capacitance $C_{w}$, a conductance $U A$ to ambient conditions, with mass flow rate $\dot{m}$ and heat input rate of $Q_{\text {elec }}$, a heat balance on the water node is as follows:

$$
Q_{\text {elec }}-\dot{m} C_{p}\left(T_{w}-T_{\text {inlet }}\right)+U A\left(T_{\text {amb }}-T_{w}\right)=C_{w} \frac{d T_{w}}{d t}
$$

Rearranging,

$$
\frac{d T_{w}}{d t}=\frac{\dot{m} C_{p} T_{\text {inlet }}+U A^{*} T_{\text {amb }}+Q_{\text {elec }}}{C_{w}}-\frac{U A+\dot{m} C_{p}}{C_{w}} * T_{w}
$$

or

$$
d t=\frac{d T_{w}}{\frac{\dot{m} C_{p} T_{\text {inlet }}+U A^{*} T_{a m b}+Q_{\text {elec }}}{C_{w}}-\frac{U A+\dot{m} C_{p}}{C_{w}} * T_{w}}
$$

The time required to change the tank's temperature from an initial temperature $T_{w, \text { initial }}$ to a new temperature $T_{w, \text { final }}$ is given by integrating that equation:

$$
t_{1}-t_{0}=\int_{T_{w=} T_{w, \text { initial }}}^{T_{w, \text { final }}}\left(\frac{d T_{w}}{\frac{\dot{m} C_{p} T_{\text {inlet }}+U A^{*} T_{a m b}+Q_{\text {elec }}}{C_{w}}-\frac{U A+\dot{m} C_{p}}{C_{w}} * T_{w}}\right)
$$


That is an integral of the form $\frac{d x}{a+b x}$, which has solution $\frac{1}{b} \ln (a+b x)$. Therefore, the final model of the time required to raise (or lower) the tank's temperature is

$$
t_{1}-t_{0}=\left.\frac{1}{b} * \log \left(a+b T_{w}\right)\right|_{T_{w}=T_{w, \text { initial }}} ^{T_{w, \text { final }}}
$$

where

$$
\begin{aligned}
a & =\frac{Q_{\text {elec }}+\dot{m} C_{p} T_{\text {inlet }}+U A * T_{\text {amb }}}{C_{w}} \\
b & =\frac{-\left(U A+\dot{m} C_{p}\right)}{C_{w}}
\end{aligned}
$$

The reverse problem of calculating the new temperature of the tank from a known initial temperature and time difference, $t_{1}-t_{0}$, follows directly:

$$
T_{\text {final }}=\frac{Q_{\text {elec }}+\dot{m} C_{p} T_{\text {inlet }}+U A^{*} T_{\text {amb }}}{U A+\dot{m} C_{p}}-\left(\frac{Q_{\text {elec }}+\dot{m} C_{p} T_{\text {inlet }}+U A^{*} T_{a m b}}{U A+\dot{m} C_{p}}-T_{\text {init }}\right) e^{b\left(t_{1}-t_{0}\right)}
$$

\subsubsection{Two-Node Temperature Model}

This model, which applies when the heater is in a state of partial depletion, considers the heater to consist of two slugs of water, each at a uniform temperature. The upper "hot" node is near the heater's setpoint temperature, while the lower "cold" node is near the inlet water temperature. The time required to change the tank's hot water column from an initial height of $\mathrm{h}_{\text {initial }}$ to a final height of $\mathrm{h}_{\text {final }}$ is given by the following equation:

$$
t_{1}-t_{0}=\frac{1}{b} * \log \left(\frac{d h_{w}}{d t}\right)_{h_{\text {initial }}}^{h_{\text {inal }}}
$$

where $d h / d t$ is the temperature gradient along the height of the water column. This is calculated as a function of mass flow rate and the temperature difference between the upper and lower interface layers of the water column, as given by the following:

$$
\frac{d h_{w}}{d t}=a+b h
$$

where

$$
\begin{aligned}
& a=\frac{-\left(\dot{m} C_{p}\right)}{C_{w}}+\frac{Q_{\text {elec }}+U A * T_{\text {amb }}}{C_{w} * T_{\text {lower }}} \\
& b=\frac{U A}{C_{w}}
\end{aligned}
$$


In the two-node model, during each synchronization cycle, the height of the hot water column is calculated based on the mass flow rate, using the following equation:

$$
h_{\text {new }}=\frac{e^{b T_{w} *}\left(a+b h_{\text {initial }}\right)-a}{b}
$$

\subsubsection{Simulation Sequence}

Each time the water heater is synchronized, the simulation follows four steps:

1. Calculate the energy consumed since the last iteration. The heater remembers whether it was heating and simply computes the consumption based on the time interval since the last synchronization.

2. Update the tank temperature or the location of the hot/cold boundary, depending on whether the tank was previously FULL, PARTIAL, or EMPTY.

3. Discern whether the tank needs heat. If the tank is in (or has reached) a FULL state at the thermostat setting, the power will be turned off. Otherwise, the element will be turned on. For the One-Node model, the heater state remains unchanged from its previous state when the water temperature is between the heating cut-off and cut-on temperatures (the dead band around the thermostat setpoint).

4. Calculate and post the time to next transition. For example, if the heater is on, this is either the time for the water to reach the cut-off temperature or for the hot/cold boundary to reach the bottom of the tank, depending on the tank state.

\subsubsection{Complicating Factors}

Several factors complicate the simulation. First, switching models between FULL, PARTIAL, and EMPTY states requires careful attention to not only what's happening now, but what state(s) things were in previously. Second, identifying when the load state is STABLE can be difficult. Finally, each of the models (One-Node and Two-Node) has two incarnations-one to calculate time to transition, and a second "inverted" one to calculate temperature/boundary location after a given amount of time. Because of limitations on floating point precision, the inverted model may not show that the water heater has actually reached the state it was anticipating. For example, the time model may show that the tank will reach the cut-off temperature of, say, $135^{\circ} \mathrm{F}$ in 12 minutes. After 12 minutes, the core synchronizes the water heater. The temperature model may calculate that the final temperature is $134.95^{\circ} \mathrm{F}$. In the worst case, the simulation could go into an infinite loop and never actually change states. 


\subsection{Lights}

Residential lighting tends to be a mixture of several different types of lighting that is distributed somewhat randomly throughout the house and across the two circuit phases. Very little residential lighting is controlled by timers, although some outdoor lighting may be controlled by daylight sensors. The residential module requires connected lighting power for each lighting fixture type to be represented in a lighting object.

Depending on its location, the heat produced by a light fixture may go entirely into the conditioned space or may be partly dumped to an unconditioned space such as an attic or directly outdoors.

\subsection{Modeling Assumptions}

- Power factor depends on the lighting type:

- Incandescent lighting: 1.00

- Fluorescent lighting: 0.95

- $\quad$ Compact fluorescent lighting (CFL): 0.92

- Solid-state lighting (SSL): 0.75

- High-intensity discharge (HID) lighting: 0.97

- The default installed capacity of each light object is based on an assumed power density that is randomly chosen between 0.75 and $1.25 \mathrm{~W} / \mathrm{ft}^{2}$. Note that this default density approximates the lighting in a whole house, so it is unlikely to be correct unless there is only one light object in the model. Because most homes have a mixture of lighting types and thus need more than one light object, the default density may need to change in the future to be type-specific (which would imply that several light objects would have to be specified to get a correct set of defaults).

- The fraction of lighting consumption that ends up as heat in the house is fixed at $90 \%$.

- The power factor of the aggregate lighting load is fixed at 0.95 .

\subsection{Modeling Approach}

Each light object will have a single type (incandescent, fluorescent, CFL, SSL, or HID) but may represent multiple fixtures in the house. It is expected that most models will contain one light object for each type of lighting present in the house, although nothing constrains that.

Each object will have an installed capacity that represents its total consumption when all fixtures represented by the object are on. The scheduling of the light object (on/off) is based on a simple demand multiplier (p.u.) that is provided from a tape module ${ }^{1}$. Future enhancements may give the lights module the ability to generate demand schedules in an intelligent (yet random) way.

Each object will have a constant power factor.

\footnotetext{
${ }^{1}$ The current implementation has a demand constant of 1.0. Tape modules are defined in GridLAB-D Technical Support Document: Tape Modules.
} 
Each object will have a constant fraction of heat that enters the conditioned space.

Thus, the energy consumption is calculated as

$$
\text { power }(\mathrm{kW}) \text { = installed_power }(\mathrm{W}) * \text { demand / } 1000
$$




\subsection{Dishwasher}

Dishwashers are fairly complex to control. Many wash cycles are simply timed prescriptions for filling, washing, releasing soaps and softeners, and drying, but most washers have several cycles to choose from. Some cycles in some dishwashers include a water temperature booster, which can be fairly energy intensive.

\subsection{Modeling Assumptions}

- Energy consumption in dishwashers is split between motors and resistance heaters. Thus, the power factor changes depending on whether the wash cycle includes water temperature boost and changes from one part of the cycle to another. At this point, however, power factor modeling is simplified to be a constant value, fixed by default at 0.95 .

- The fraction of washer consumption that becomes heat in the space is arbitrarily estimated to be $50 \%$. This presumes that half the heat generated by the motors and resistance heater is transferred to the water and flushed down the drain.

- Installed capacity (installed_power in the following modeling approach) is a randomly selected value ${ }^{2}$ between $1000 \mathrm{~W}$ and $3000 \mathrm{~W}$.

\subsection{Modeling Approach}

Dishwashers are modeled as a simple stream of energy demand signals taken from a tape module. That is,

$$
\text { power }(\mathrm{kW})=\text { installed_power * demand / } 1000
$$

The heat gains to the space are simply

$$
\text { internal_heat }(\mathrm{kW})=\text { power * heat_fraction }
$$

\footnotetext{
${ }^{2}$ The $1000 \mathrm{~W}$ might be too high for dishwashers without temperature boost.
} 


\subsection{Range}

Electric ranges are essentially perfectly resistive loads. Each burner on a range top may be controlled by cycling the power on and off or by a triac device that regulates the on time at very high frequency. The user may reset the knob setting multiple times during a cooking event. Thus, range loads vary with the number of active burners, the user-controlled knob settings, and possibly the cycling behavior.

The GridLAB-D range model is greatly simplified to be identical to the way plug loads are modeled — a demand ( 0 to 1 ) is read from a tape module and multiplied by a range object-specific capacity (installed_power).

\subsection{Modeling Assumptions}

- Power factor is assumed to be fixed at 0.95 .

- $100 \%$ of the range's energy consumption is assumed to enter the house as heat (ignoring the heat that goes into the food).

- Installed capacity (installed_power in the following modeling approach) is randomly selected between $2500 \mathrm{~W}$ and $4500 \mathrm{~W}$.

\subsection{Modeling Approach}

The range model retrieves its demand from a tape module as a simple stream of values between 0 and 1 (representing the fraction of time that the power is on). The demand is adjusted (scaled) by an "installed_power" value associated with each microwave (W). That is,

$$
\text { power }(\mathrm{kW}) \text { = installed_power * demand / } 1000
$$

The heat gains to the space are simply

$$
\text { internal_heat }(\mathrm{kW})=\text { power } * \text { heat_fraction }
$$




\subsection{Microwave}

In their simplest mode of operation (full power), microwave ovens consume an essentially constant power. Other modes, such as defrost or partial-power, typically consume the same power in cycled on-off bursts. Microwaves are typically rated at 750 to $1100 \mathrm{~W}$ and operate at an efficiency in the neighborhood of $65 \%$, meaning that $65 \%$ of the energy consumed goes toward heating food and the rest is released as heat to the surroundings. However the heat released to the surroundings is complicated. Although roughly $35 \%$ of consumed energy goes immediately to the house as heat, the $65 \%$ that warms the food is arguably released eventually as heat, either as the food cools on the table or as it is released as body heat from the humans who ate it.

\subsection{Modeling Assumptions}

- Power factor is assumed to be fixed at 0.95 .

- Because microwaves have efficiencies in the range of $75 \%$, approximately $25 \%$ of their consumption goes immediately to the space as heat. Because body heat from occupants is theoretically accounted for separately, the microwave model assumes that none of the remaining energy consumption becomes heat in the space.

- Installed capacity (installed_power in the following modeling approach) is a randomly selected value ${ }^{3}$ between $700 \mathrm{~W}$ and $2000 \mathrm{~W}$.

\subsection{Modeling Approach}

The microwave model retrieves its demand from a tape module as a simple stream of values between 0 and 1 (representing the fraction of time that the power is on). Ordinarily, the values will be either 0 or 1 because most microwaves control cooking by cycling. The demand is adjusted (scaled) by an “installed_power” value associated with each microwave (W). That is,

$$
\text { power }(\mathrm{kW})=\text { installed_power } * \text { demand } / 1000
$$

The heat gains to the space are simply

$$
\text { internal_heat }(\mathrm{kW})=\text { power * heat_fraction }
$$

\footnotetext{
${ }^{3}$ Most microwaves do not exceed about $1200 \mathrm{~W}$; otherwise the food cooks too fast (i.e., burns) and may trigger breakers.
} 


\subsection{Refrigerator}

The thermal and the electric loads on a refrigerator can be estimated using simplified first principles models. In this approach, the thermal load (primarily heat gain from the ambient environment) is modeled as function of a few lumped parameters (effective shell conductance, effective thermal mass, and compressor efficiency), ambient condition, internal gains adding and removing food material, and thermostat setting. Once the thermal load is estimated, the power consumption of the compressor and the fan can be calculated. Although this approach is not as detailed and accurate as the detailed physical model, it does provide reasonably accurate estimates of the energy consumption.

\subsection{Load Calculation}

The major heat gains that contribute to the refrigerator thermal load are the following:

- conduction through refrigerator/freezer walls

- heat gain from infiltration of ambient air when the refrigerator/freezer door is opened

- heat gain from additions of food to the refrigerator/freezer.

In general, the amount of heat that must be removed (cooling load) is not always equal to the amount of heat received at a given time. The difference is a result of the heat storage and time lag effects. Only a portion of the heat entering the refrigerator actually cools the air inside the refrigerator immediately; the rest cools the mass - the food material. The heat that is stored in the mass will result in thermal load at a later time. So, the modeling approach needs to account for the storage effect.

\subsection{Modeling Assumptions}

- Power factor is assumed to be fixed at 0.95 .

- The thermal conductance of refrigerator and freezer compartments are assumed to be random normal in the range of 0.9 to $1.1 \mathrm{Btu} / \mathrm{hr}^{\circ} \mathrm{ft}^{2} .^{\circ} \mathrm{F}$

- The refrigerator compartment setpoint is assumed to be between 35 and $39^{\circ} \mathrm{F}$.

\subsection{Modeling Approach}

The refrigerator model is currently implemented in its simplest form to calculate the time to change of state based on the current indoor temperature, refrigerator interior temperature, thermal properties of the casing, and food content and water content of the refrigerator compartment. The original ordinary differential equation (ODE) relating these properties is shown in Equation 7.1.

$$
\frac{C_{f}}{U A_{r}+U A_{f}}=\frac{d T_{\text {air }}}{d t}+T_{\text {air }}=T_{\text {out }}+\frac{Q_{r}}{U A_{r}}
$$

where

$T_{\text {air }}=$ the temperature of the water 
$T_{\text {out }}=$ the ambient temperature around the refrigerator

$U A_{r}=$ the thermal conductance of the refrigerator shell

$U A_{f}=$ the thermal conductance of the food-air

$C_{f}=$ the heat capacity of the food

$Q_{r}=$ the heat rate from the cooling system

The general solution for the ODE in Equation 7.1 is given below:

$$
T_{t}=\left(T_{o}-C_{2}\right) e \frac{-t}{C_{1}}+C_{2}
$$

where

$\mathrm{t}=$ the elapsed time

$\mathrm{T}_{0}=$ the initial temperature

$\mathrm{T}_{\mathrm{t}}=$ the temperature at time $\mathrm{t}$

$C_{1}=\frac{C_{f}}{U A_{r}+U A_{f}}$

$C_{2}=T_{\text {out }}+\frac{Q_{r}}{U A_{f}}$

Time to solution is:

$$
t=-\operatorname{lr} \frac{T_{t}-C_{2}}{T_{0}-C_{2}} * C_{1}
$$

During each synchronization cycle, the refrigerator model calculates the internal gain based on the rated capacity of the refrigerator and returns the time solution for determining the next synchronization time. 


\subsection{Internal Gains}

Each house modeled in GridLAB-D has two primary sources of internally generated heat. First, is the "waste" heat given off by other devices in the house that are modeled by GridLAB-D. For example, a refrigerator located inside the house is modeled primarily for its thermal behavior regarding cooling and freezing food, with its primary output being the impact (energy and peak) on the grid. However, the refrigerator also gives off heat that must be accounted for in the simulation of the house itself. Second, some devices in the home are not explicitly modeled by GridLAB-D, but those devices that have sufficient aggregate impact of their heat contribution to the house and their aggregate impact on the home's electricity must be accounted for. Examples are televisions, vacuums, hair dryers, and other miscellaneous equipment generally plugged into wall outlets.

\subsection{Modeling Assumptions}

- All "plug loads" are assumed to be consolidated into a single load. Thus, they are all either on one side of the home's circuit split or evenly distributed between the two sides; this is determined randomly when the house object is created.

- The installed capacity of plug loads is randomly set to a value between $700 \mathrm{~W}$ and $2000 \mathrm{~W}$.

- The fraction of plug load consumption that ends up as heat in the house is fixed at $90 \%$.

- The power factor of the aggregate plug loads is fixed at 0.95 .

- $\quad$ The default power demand fraction is assumed to be between 0 and 0.1 .

\subsection{Modeling Approach}

The internal gains reported by modeled devices are simply collected and summed at the house level, the house object being unaware of any details other than the consumption, circuit, and power factor reported by each device.

Other internal gains (that is, plug loads) are modeled as a simple, fixed capacity (installed power) that is multiplied at each time step by a demand fraction (p.u.) that can be supplied from a tape module. That is,

$$
\text { power }(\mathrm{kW})=\text { installed_power }(\mathrm{W}) * \text { demand } / 1000
$$

Further, the heat to the surrounding space is given by

$$
\text { internal_heat }=\text { power } * \text { heat_fraction }
$$




\subsection{House}

Estimating end-use energy consumption that accurately reflects the magnitude, average hourly shape, and probability and variance of the load is critical for the GridWise simulation and analysis work. Although there are several existing end-use modeling tools, they are not suitable because they require large amounts of detailed characteristics data as inputs to estimate heating/cooling/ventilation end-uses (EnergyPlus, HVACSim, and TRANSYS), while others are not suitable because they do not support time steps shorter than an hour (DOE 2.1, BLAST, and ASEAM). In addition, such detailed simulation models require significant amount of CPU time to estimate end-uses and, therefore, cannot be scaled to meet the requirement of simulating 1,000 or more residences in real time using today's desktop computers.

The thermal loads in a residential and small commercial building can be estimated using simplified first principles models. In this approach, the cooling and heating loads are modeled as functions of a few lumped parameters (effective envelop conductance, effective thermal mass and effective solar apertures, ventilation/infiltration rates, and equipment efficiencies), weather, internal gains from equipment and occupants, and thermostat setpoints. Although this approach is not as detailed and accurate as the detailed simulation models, it does overcome some of the limitations and provides reasonably accurate results.

In the remainder of this house object discussion, we describe the residential and small commercial building thermal load calculation, the modeling approach, major assumptions, and model testing and validation.

\subsection{Load Calculation}

The major heat gains and losses that contribute to the building cooling or heating load consist of the following:

1. conduction through exterior walls, roof, and glass

2. heat gain/loss from infiltration of outside air through openings

3. solar radiation through glass

4. internal gains from lighting, people, equipment.

Items 1, 2, and 3 are considered to be driven by the external source, while item 4 is considered to be internally generated. The thermal load can be either sensible or latent. Sensible load results in increase/decrease in the air temperature; latent load results in increase/decrease of water vapor, which increases/decreases the humidity. Items 1 and 3 are solely sensible; item 2 can be both sensible and latent; internal gains from lights are sensible; internal gains from people and equipment can be both sensible and latent.

In general, the amount of heat that must be removed (cooling load) or added (heating load) is not always equal to the amount of heat received or lost at a given time. The difference is a result of the heat storage and time lag effects. Only a portion of the heat entering or leaving the building actually heats or cools the room air immediately; the rest heats the building mass—-the roof, walls, floors, building mass, 
and air mass. The heat that is stored in the mass will result in heating/cooling load at a later time. Thus, the modeling approach will have to account for the storage effect.

To account for the storage effects when estimating the conduction gains from the exterior walls, roofs, and glass, the cooling load temperature difference (CLTD) method can be used:

$$
\mathrm{Q}=\mathrm{U} * \mathrm{~A} * \mathrm{CLTD}_{\mathrm{c}}
$$

where

$\mathrm{Q}=$ cooling load for roof, wall or glass (Btu/hr)

$\mathrm{U}=$ overall heat transfer coefficient for roof, wall, or glass $\left(\mathrm{Btu} / \mathrm{hr}-\mathrm{ft}^{2}-{ }^{\circ} \mathrm{F}\right)$

$\mathrm{A}=$ area of roof, wall or glass $\left(\mathrm{ft}^{2}\right)$

$\mathrm{CLTD}_{\mathrm{c}}=$ corrected cooling load temperature difference $\left({ }^{\circ} \mathrm{F}\right)$.

The CLTD is not the actual temperature difference between the outdoor and indoor air. It is a modified value that accounts of storage effects (Pita 2002). The CLTD values for selected roofs and wall constructions are published in the literature (Pita 2002, ASHRAE 2001).

The published CTLD values are based on the following conditions:

1. indoor temperature is $78^{\circ} \mathrm{F}$.

2. outdoor average temperature on the design day is $85^{\circ} \mathrm{F}$.

3. date is July $21^{\text {st }}$.

4. location is $40^{\circ} \mathrm{N}$ latitude.

Because the actual conditions differ from any of the above, the CLTD must be corrected:

$$
\mathrm{CLTD}_{\mathrm{c}}=\mathrm{CLTD}+\mathrm{LM}+\left(78-\mathrm{T}_{\text {air }}\right)+\left(\mathrm{T}_{\mathrm{a}}-85\right)
$$

where

$\mathrm{CLTD}_{\mathrm{c}}=$ corrected value of CLTD $\left({ }^{\circ} \mathrm{F}\right)$

CLTD $=$ temperature difference from tables

$\mathrm{LM}=$ correction for latitude and month, from tables

$\mathrm{T}_{\text {air }}=$ room temperature $\left({ }^{\circ} \mathrm{F}\right)$

$\mathrm{T}_{\mathrm{a}}=$ average outside temperature on a design day $\left({ }^{\circ} \mathrm{F}\right)$.

\subsection{Modeling Assumptions}

The house model assumes that only envelope characteristics, solar gain through windows and internal gain contribute to the heating, ventilation, and air conditioning (HVAC) load. Only air conditioners and heat pumps are modeled in the current implementation.

\subsection{Modeling Approach}

The modeling approach that is used to estimate thermal loads is called an equivalent thermal parameter (ETP) modeling approach. This modeling approach has been chosen for the current work because it has been proven to reasonably model residential (and small commercial building) loads and energy consumption and also because it is based on first principles (Sonderegger 1978 Subbarao 1981 
Wilson et al. 1985 Taylor and Pratt 1988). The electric circuit analog of an ETP model that is used to simulate heating and cooling loads in a typical residence is shown in Figure 9.1. The heat transfer properties are represented by equivalent electrical components with associated parameters for modeling the thermostatically controlled HVAC system.

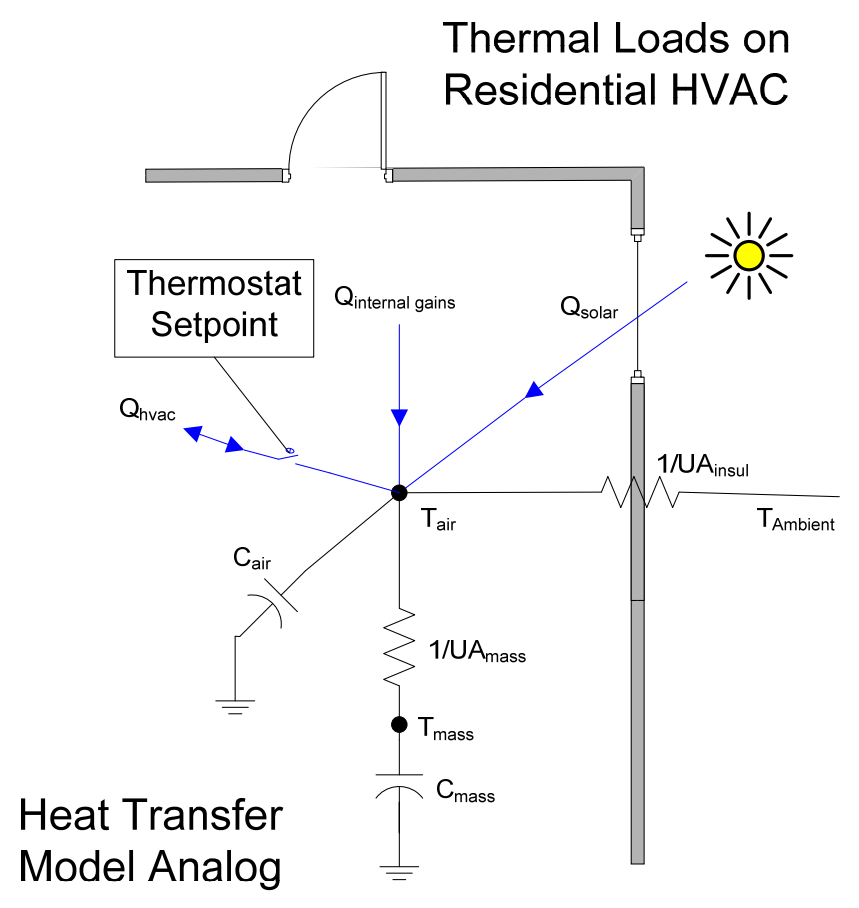

where

Figure 9.1. ETP Representation of Typical Residences

$C_{\text {air }}=$ air heat capacity $\left(\mathrm{Btu} /{ }^{\circ} \mathrm{F}\right.$ or joules $\left./{ }^{\circ} \mathrm{C}\right)$

$C_{\text {mass }}=$ mass (of the building and its content) heat capacity $\left(\mathrm{Btu} /{ }^{\circ} \mathrm{F}\right.$ or joules $/{ }^{\circ} \mathrm{C}$ )

$U A_{\text {insul }}=$ the gain $/$ heat loss coefficient $\left(\mathrm{Btu} /{ }^{\circ} \mathrm{F} \cdot \mathrm{hr}\right.$ or $\left.\mathrm{W} /{ }^{\circ} \mathrm{C}\right)$ to the ambient

$U A_{\text {mass }}=$ the gain/heat loss coefficient $\left(\mathrm{Btu} /{ }^{\circ} \mathrm{F} \cdot \mathrm{hr}\right.$ or $\left.\mathrm{W} /{ }^{\circ} \mathrm{C}\right)$ between air and mass

$T_{o}=\mathrm{CLTD}_{\mathrm{c}}+\mathrm{T}_{\mathrm{air}}\left({ }^{\circ} \mathrm{F}\right.$ or $\left.{ }^{\circ} \mathrm{C}\right)$

$T_{\text {ambient }}=$ ambient temperature $\left({ }^{\circ} \mathrm{F}\right.$ or ${ }^{\circ} \mathrm{C}$ )

$T_{\text {air }}=$ air temperature inside the house $\left({ }^{\circ} \mathrm{F}\right.$ or $\left.{ }^{\circ} \mathrm{C}\right)$

$T_{\text {mass }}=$ mass temperature inside the house $\left({ }^{\circ} \mathrm{F}\right.$ or $\left.{ }^{\circ} \mathrm{C}\right)$

$Q_{\text {HVAC }}=$ heat rate for HVAC (Btu/hr or watts)

$Q_{\text {internal gains }}=$ heat rate from other appliance, plug loads, lights, and people in the residence (Btu/hr or watts)

$Q_{\text {solar }}=$ heat gain from solar (Btu/hr or watts)

A state space description of the ETP model is: 


$$
\begin{aligned}
& \dot{x}=A x+B u \\
& y=C x+D u \\
& \dot{X}=\left[\begin{array}{c}
\dot{T}_{\text {air }} \\
\dot{T}_{\text {mass }}
\end{array}\right] \quad x=\left[\begin{array}{c}
T_{\text {air }} \\
T_{\text {mass }}
\end{array}\right] \quad u=1 \\
& \mathrm{~A}=\left[\begin{array}{cc}
-\left(\frac{1}{R_{2} C_{\text {air }}}+\frac{1}{R_{1} C_{\text {air }}}\right) & \frac{1}{R_{2} C_{\text {air }}} \\
\frac{1}{R_{2} C_{\text {mass }}} & -\frac{1}{R_{2} C_{\text {mass }}}
\end{array}\right] \quad B=\left[\begin{array}{c}
\frac{T_{0}}{R_{1} C_{\text {air }}}+\frac{Q}{C_{\text {air }}} \\
0
\end{array}\right] \\
& C=\left[\begin{array}{ll}
1 & 0 \\
0 & 1
\end{array}\right] \quad D=\left[\begin{array}{l}
0 \\
0
\end{array}\right]
\end{aligned}
$$

where

$R_{1}-1 / \mathrm{UA}_{\text {insul }}$

$R_{2}-1 / \mathrm{UA}_{\text {mass }}$

$Q-Q_{H V A C}+Q_{\text {solar }}+Q_{\text {internal gains }}$

Because there is wide diversity in the thermal parameters (heat gain/loss coefficient, mass, efficiency of equipment, and oversizing factor) used to compute the load across homes, ranges can be provided for these parameters. Because of regional difference in construction practices and wide variation even within a region, a range of values can be assigned for critical parameters based on metering studies (Pratt et al. 1990). While estimating energy consumption of individual homes, the thermal parameters are randomly assigned to each home (from the established range using a known distribution, for example, uniform).

The internal gains in the home are computed external to the house object and are assumed to be inputs to the ETP model. These gains represent heat from other appliances (such as range, microwave), plug loads, lights, and people.

Solving the ETP model (simultaneously for $T_{\text {air }}$ and $T_{\text {mass }}$ ), we can obtain the cooling/heating load of an individual home as a function of time. The energy consumption to meet the comfort needs in the home can then be computed by converting the thermal loads by using typical manufacturer-provided air conditioner part load performance data. Using the same simulation model, the energy consumption of a population of homes can also be computed. While simulating a population of homes, the energy consumption for each home is computed simultaneously at each time step. Therefore, the model provides an accurate representation of distribution feeder load when electric loads are aggregated.

A single ETP model with different thermal parameters can be used to represent all homes in the population for simplicity, or if there is a need, multiple ETP models with different thermal parameters can be used. Therefore, in addition to changing input parameters while simulating a population of homes, the ETP model can also be changed to accurately represent a given building stock. This ensures that it accurately reproduces the effects of load diversity. 


\subsection{Limitation and Future Improvements}

The approach described in the previous section only accounts for sensible loads. This limitation does not lead to a significant error in heating load calculation (because most heating load is sensible); it does lead to some error in the estimation of the cooling load. 


\subsection{References}

ASHRAE, 2001, ASHRAE Fundamentals 2001, American Society of Heating, Refrigerating and AirConditioning Engineers, Atlanta, GA.

Pita, GE. 2002. Air-Conditioning Principles and Systems. Prentice Hall, Upper Saddle River, New Jersey.

Pratt, RG, CC Conner, MK Drost, NE Miller, BA Cooke, MA Halverson, BA Lebaron, RG Lucas, J Jo, EE Richman, WF Sandusky, KG Ritland, and ME Taylor. 1990. "Significant ELCAP Analysis Results: Summary Report.” PNL-6659, Pacific Northwest National Laboratory, Richland, Washington.

Sonderegger, R 1978. "Dynamic Models of House Heating Based on Equivalent Thermal Parameters.” Report PU/CES 57, Ph.D. Dissertation, Princeton University, Princeton, New Jersey.

Subbarao, K. 1981. “Thermal Parameters for Single and Multizone Buildings and Their Determination from Performance Data.” Solar Energy Research Institute, Golden, Colorado.

Taylor, Z and RG Pratt. 1988. "The Effects of Model Simplifications on Equivalent Thermal Parameters Calculated from Hourly Building Performance Data." Procedings of the 1988 ACEEE Summer Study on Energy Efficiency in Buildings, Volume 10, pp 268-285. American Council for an Energy-Efficient Economy, August 1988.

Wilson, NW, BS Wagner, and WG Colborne. 1985. "Equivalent Thermal Parameters for an Occupied Gas-Heated House.” ASHRAE Transactions. 91:2. 